Article

\title{
Lower Postprandial Thermogenic Response to an Unprocessed Whole Food Meal Compared to an Iso-Energetic/Macronutrient Meal Replacement in Young Women: A Single-Blind Randomized Cross-Over Trial
}

\author{
Alex E. Mohr ${ }^{1}$ (D), Carmen Ramos ${ }^{2,+}$, Kelvin Tavarez ${ }^{2,+}$ and Paul J. Arciero $2,3, *$ (D) \\ 1 College of Health Solutions, Arizona State University, Phoenix, AZ 85004, USA; aemohr@asu.edu \\ 2 Department of Health and Human Physiological Sciences, Skidmore College, Saratoga Springs, NY 12866, \\ USA; cramos@skidmore.edu (C.R.); ktavarez@skidmore.edu (K.T.) \\ 3 Human Nutrition and Metabolism Laboratory, Skidmore College, Saratoga Springs, NY 12866, USA \\ * Correspondence: parciero@skidmore.edu; Tel.: +1-518-859-0935 \\ + These authors contributed equally to this manuscript.
}

Received: 13 July 2020; Accepted: 13 August 2020; Published: 17 August 2020

check for updates

\begin{abstract}
In contrast to ultra-processed foods that are associated with increased weight gain and obesity risk, nutritionally engineered dietary supplements, including meal replacement (MR) bars and shakes, are generally promoted as healthy. Limited data is available comparing the metabolic and hunger responses of whole food (WF) versus MR meals. The purpose of this study was to directly compare the thermic effect (TEM), respiratory exchange ratio (RER), hunger/taste ratings, and glucose response of two different breakfast meals containing MR and WF products in young healthy women. Eight volunteers completed two iso-caloric (529 kcals)/macronutrient (50\% carbohydrates; $26 \%$ fat; $24 \%$ protein) test meals in a single-blind, randomized crossover design: (1) whole food meal; or (2) meal replacement. TEM was significantly higher following MR compared with WF (percent mean difference: $7.76 \pm 3.78 \%$; absolute mean difference: $0.053 \pm 0.026 \mathrm{kcal} / \mathrm{minute}, p=0.048)$, whereas WF substrate utilization demonstrated lower carbohydrate oxidation (RER) than MR (mean difference: $-0.024 \pm 0.008, p=0.005)$. No differences existed for blood glucose response and feelings of hunger, desire to eat, and satiety among trials. Consumption of an MR meal increases postprandial thermogenesis and RER compared to a WF meal, which may impact weight control and obesity risk over the long-term.
\end{abstract}

Keywords: meal replacement; nutritionally engineered food; ultra-processed food

\section{Introduction}

The demand and consumption of ultra-processed/refined food (PF) options, including packaged, pre-made, and fast food items, have steadily increased over recent decades and are becoming a dominant feature in the global food system [1,2]. Unfortunately, obesity and metabolic disorders are often associated with increased consumption of ultra PFs [3-5]. Paralleling this increased consumption of ultra PF is the increased intake of dietary supplements [6], including meal replacement (MR) bars and shakes, which unlike other PFs, are generally promoted as healthy. Indeed, MR options are often used in weight loss interventions due to similar or better nutritional values compared to whole food (WF) mixed meals [7,8]. As such, these 'nutritionally engineered' MR foods exhibit certain superior health benefits compared to many WF options. Specifically, medium to long-term weight loss interventions using nutritionally engineered MR shakes and/or bars have demonstrated 
enhanced weight/fat loss, improved cardiometabolic outcomes, and dietary adherence compared to traditional WF meal options [9-12]. However, it is less understood whether these products may increase postprandial thermogenesis and decrease hunger responses to an acute meal challenge in younger healthy adults.

Previous work from our laboratory has assessed both acute and chronic effects of different meal compositions and ingestion patterns utilizing nutritionally engineered MR meals [12-14]. For instance, compared to a traditional feeding schedule of three meals per day, increasing protein intake evenly throughout the day (protein pacing) improved body composition and metabolism over an eight-week intervention [12]. Further, a pancake meal breakfast combining resistant starch and whey protein was found to increase fat oxidation, peptide $Y Y$, and satiety response compared to a carbohydrate starch control, resistant starch alone, and control starch with protein [13]. More recently, we have examined the acute effects of sandwich meals with differing levels of food processing on postprandial thermogenesis, substrate utilization, hunger/taste ratings, and glucose response [14] and reported a PF meal consisting of gluten free (GF) ingredients produces a significantly lower thermogenic response (calorie burn) compared to a WF or ultra PF meal of equal caloric and macronutrient composition. In addition, the WF meal resulted in a greater sensation of fullness compared to GF and PF conditions. This line of research has substantial public health implications regarding how specific dietary advice is recommended based on food processing and ingredient selection to better optimize body weight control and composition.

Another important consideration is the physical form of the test meals, with multiple studies reporting greater energy intake and appetite after acute meal challenges with liquid compared to solid food forms [15-17], although this is not a universal finding [18-20]. Many of the food products used in these studies were single items, and therefore, less reported is the effect of MR liquid shakes and/or bars in comparison to a mixed, WF meal. Previous research in older adults and adolescents shows acute ingestion of a breakfast MR blunts satiety and increases subsequent food intake [21-25]. To our knowledge, only one study has directly compared a breakfast MR to a WF cereal and milk meal in young adults, showing no differences in thirst, hunger, appetite, or subsequent dietary intake [26]. Less data exists on the thermogenic responses to acute MR versus WF meal challenges in young healthy women. Given the adverse body weight and composition changes during the transition from high school to university living [27], college-aged women are susceptible to weight gain due to poor nutrition habits [28]. Based on this previous literature, it was hypothesized that energy expenditure and satiety would be greater in the WF compared to MR breakfast meal, whereas glucose and substrate utilization would be similar.

Thus, a better understanding of the metabolic and hunger responses to MR versus WF meals may provide important information regarding improved body weight management and obesity risk in young adult women. Therefore, the purpose of this study was to systematically compare the thermogenic response, hunger ratings, and blood glucose of MR and WF breakfast meals matched for energy and macronutrient composition in healthy, young college-aged women.

\section{Materials and Methods}

\subsection{Participants}

A total of 10 women from the Saratoga Springs, NY local college (Skidmore College) were recruited through email and initially screened, of whom all were eligible for participation during the spring of 2015. Participants were non-smoking, healthy women between the ages of 18-24 years with no known cardiovascular or metabolic diseases as assessed by a medical history and examination by their personal physicians. Participants with lactose intolerance/sensitivity, diabetes mellitus, and hypoglycemia were ineligible to participate in the study. To prevent possible influence on data, participants who engaged in excess use of dietary supplements were also excluded from the study. Each participant provided informed written consent in adherence with the Skidmore College Human Subjects review board prior 
to participation, and the study was approved by the Human Subjects Institutional Review Board of Skidmore College (IRB\#: 1302-333). All experimental procedures were performed in accordance with the Federal Wide Assurance and related New York State regulations, which are consistent with the National Commission for the Protection of Human Subjects of Biomedical and Behavioral Research and in agreement with the Helsinki Declaration as revised in 1983. This trial was registered at clinicaltrials.gov as NCT04453254.

\subsection{Experimental Design}

Upon recruitment, participants visited the Human Nutrition and Metabolism Laboratory for a $1 \mathrm{~h}$ initial meeting to complete a medical questionnaire and informed consent form as well as have their body composition assessed via a dual-energy x-ray absorptiometry (DXA) scan. Measurements of height and body weight were taken using standard laboratory equipment and procedures. Pre-testing instructions were also given, which consisted of (a) refraining from eating or drinking 8-10 h before testing, (b) eating and drinking normally for the $48 \mathrm{~h}$ preceding the $8-10 \mathrm{~h}$ fast, (c) refraining from drinking coffee or alcohol $48 \mathrm{~h}$ prior to testing, (d) preventing any excess physical activity the day prior to testing, and (e) maintaining a food log for the three preceding days of testing.

Participants were instructed to go to bed by $11 \mathrm{pm}$ the night prior to testing and were transported by car to the Human Nutrition and Metabolism Laboratory by 6:30 am. Upon arriving to the lab, baseline measurements were conducted and participants were then given $15 \mathrm{~min}$ to ingest the assigned meal. Subsequent measurements were conducted as outlined in Figure 1.

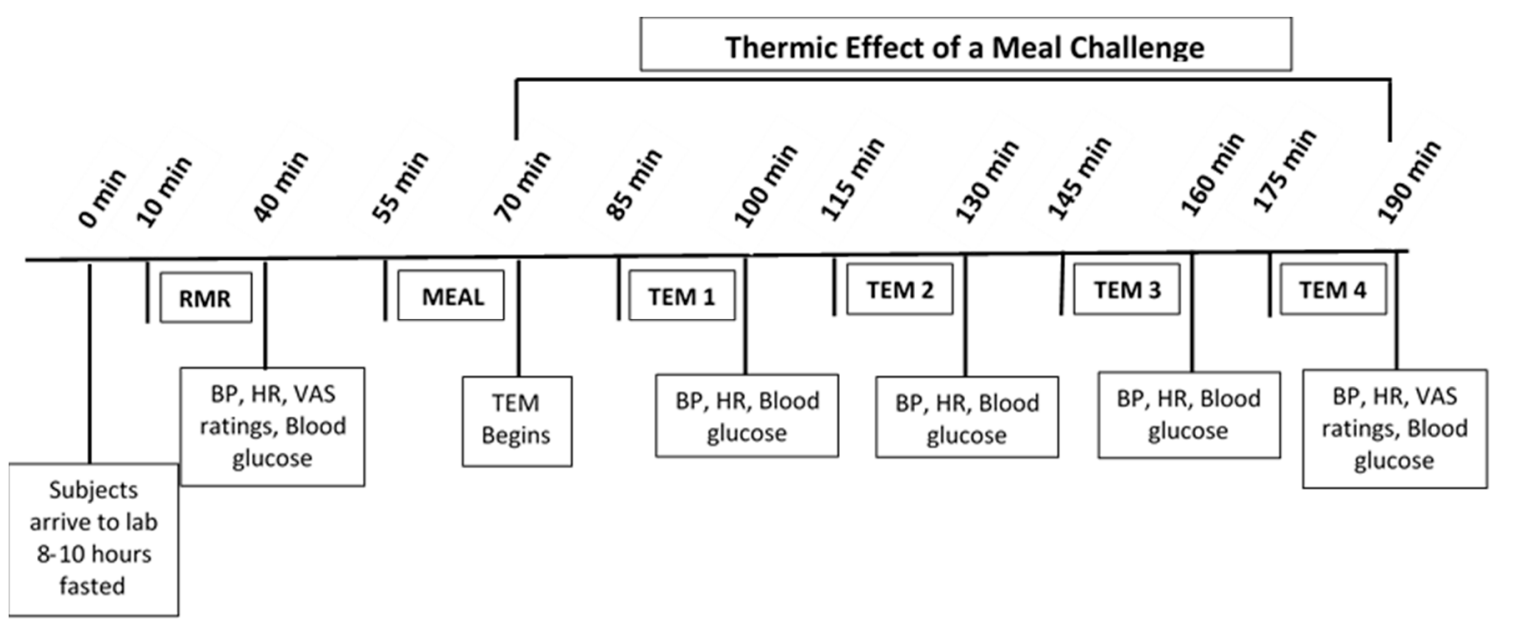

Figure 1. Timeline of thermic effect of a meal (TEM) test days. RMR: resting metabolic rate; BP: blood pressure; HR: heart rate; VAS: visual analog scales for hunger, fullness, satiation, desire to eat.

After a one-week washout period, the participants returned to the lab to repeat the same procedure with the other test meal. The order in which the meals were prescribed was random and balanced.

\subsection{Test Meals}

On two separate visits to the Human Nutrition and Metabolism Laboratory, all subjects consumed one of two test meals in a single-blind, randomized repeated-measures crossover design: (1) meal replacement meal (MR; $n=8) ;(2)$ whole foods meal (WF; $n=8)$. The WF meal and the MR meal were composed so that caloric and macronutrient composition were equal Table 1. 
Table 1. Nutritional analysis and ingredients of the two test meals.

\begin{tabular}{lll}
\hline Nutritional Analysis & WF & MR \\
\hline Energy (kcal) & 529 & 529 \\
Total carbohydrate $(\mathrm{g})$ & $69(50 \%)$ & $69(50 \%)$ \\
Total sugar $(\mathrm{g})$ & 27.6 & 50.7 \\
Total fat $(\mathrm{g})$ & $16(26 \%)$ & $16(26 \%)$ \\
Total saturated fat $(\mathrm{g})$ & 5.3 & 3.8 \\
Total protein $(\mathrm{g})$ & $32(24 \%)$ & $32(24 \%)$ \\
Total fiber $(\mathrm{g})$ & 19.7 & 1.7 \\
\hline & $2 \%$ milk $(305 \mathrm{~g})$ & Boost High-Protein Nutritional Drink $(224 \mathrm{~g})$ \\
& Kashi Go-Lean Original cereal $(63 \mathrm{~g})$ & Canola oil (3 g) \\
Ingredients & Almonds (28 g) & Honey (21 g) \\
& Raspberries $(41 \mathrm{~g})$ & Met-Rx Big 100 Colossal Crispy Apple Pie Meal Bar (63 g) \\
\hline
\end{tabular}

WF: whole food meal; MR: meal replacement.

\subsection{Resting Metabolic Rate (RMR) and Thermic Effect of a Meal (TEM)}

RMR was measured upon arrival using the ventilated hood system with a computerized open-circuit indirect calorimeter as previously described [13]. Briefly, upon arrival to the lab, participants rested quietly for $10 \mathrm{~min}$ and then were instructed to lie down and have their resting metabolic rate (RMR) measured for $30 \mathrm{~min}$ using a metabolic cart, ventilated hood system, and mixing chamber (ParvoMedics TrueOne 2400 Metabolic Measurement System, Sandy, UT, USA). Following RMR and other baseline measurements, participants underwent a thermic effect of a meal (TEM) challenge within 15 min. Following meal ingestion, participants rested quietly for $2 \mathrm{~h}$ during which time their RMR was measured every other $15 \mathrm{~min}$ for $15 \mathrm{~min}$ (i.e., measurements taken at minutes: 15-30, 45-60, 75-90, and 105-120, postprandially).

\subsection{Respiratory Exchange Ratio (RER)}

RER was calculated from indirect calorimetry gas exchange as the volume of carbon dioxide produced to the volume of oxygen consumed $\left(\mathrm{VCO}_{2} / \mathrm{VO}^{2}\right)$ (Parvomedics, Truemax 2400, Sandy, UT, USA) and were calculated using the exact same method described above for $120 \mathrm{~min}$ TEM.

\subsection{Visual Analog Scale (VAS) Measures}

Baseline measurements of subjective ratings of hunger, fullness, and desire to eat were evaluated using a $100 \mathrm{~mm}$ visual analog scale (VAS). Participants were prompted with four questions regarding hunger, fullness, and desire to eat and were then asked to draw a vertical line on the VAS scale representing how they felt at that moment. A vertical line mark at $0 \mathrm{~mm}$ represented no feelings, whereas a mark at $100 \mathrm{~mm}$ indicated extreme feelings. The degree to which each sensation was felt was quantified by measuring how far the mark was from the $0 \mathrm{~mm}$ point. A standard millimeter ruler was used for all measurements and all scores were computed by the same investigator. At the completion of the 120 min test period, hunger, fullness, and desire to eat were all reevaluated.

\subsection{Blood Pressure and Heart Rate}

Resting heart rate and blood pressure were manually recorded in the supine position as previously described [13]. Heart rate was obtained by palpation from the radial pulse for $1 \mathrm{~min}$ and blood pressure measurements were obtained using a sphygmomanometer (American Diagnostic Corp., 55 Commerce Drive, Hauppauge, NY, USA) and stethoscope (Littman Quality, USA, St. Paul, MN, USA) by a trained investigator on each of the three test meal days following the RMR measurement. 


\subsection{Blood Glucose Measure}

Immediately following the RMR measurements, subjects underwent a finger stick for the assessment of blood glucose using a OneTouch Blood Glucose Analyzer (LifeScan IP Holdings, LLC., Malvern, PA, USA). Blood glucose were then measured every 30 min thereafter.

\subsection{Data Analysis}

Normality statistics (Shapiro-Wilk's tests and skewness and kurtosis z-scores) and probability plots (Q-Q plots and histograms) were generated to test normality assumptions, and log transformations were performed as appropriate. Area under the curve (AUC), and absolute and percent changes were conducted as described previously [13,29]. Briefly, blood glucose and thermic effect of meal (TEM) area under curve (AUC) were calculated by the trapezoidal rule for the entire $120 \mathrm{~min}$ postprandial period as an additional evaluative method. TEM of each meal was calculated using the difference between baseline energy expenditure levels and the increase in energy expenditure throughout the two hours of testing post-consumption of the meal. To determine the effect of meal type on the outcome variables, linear mixed-effects models were employed with a random intercept for subject, and time and meal type as fixed factors. Additionally, to assess whether the effect of meal type was different between time points, an interaction term was added to the model (meal*time). This model provides unbiased estimates of time and treatment effects under a missing-at-random assumption. Relevant covariates (i.e., body mass index (BMI), age, and baseline values) were added to the model to adjust for possible confounding. Multiple comparisons were made on generated estimated marginal means for both main effects (time and meal) and interaction effects (time*meal) with Bonferroni post-hoc tests. Absolute postprandial TEM and glucose AUC were compared by independent $t$-tests. Due to the limited data in this area, power analysis and sample size were based on previous research comparing the thermic effect of breakfast meals with differing macronutrient composition in healthy young females [28]. Based on an estimated effect size of $d=1.60$, with a power $=0.80$ and $\alpha$-level at 0.05 , we estimated a total sample size of eight participants to detect a significant effect in postprandial TEM between meals (G*Power 3.1). All analyses were performed using SPSS 26.0 for Windows (SPSS Inc.). An $\alpha$-level was set at a significance of $p<0.05$. Data are shown as mean values (with standard error) unless otherwise noted.

\section{Results}

\subsection{Participants and Compliance}

The physical characteristics of the eight college-aged females in the study are presented in Table 2.

Table 2. Subject characteristics ${ }^{a}$.

\begin{tabular}{cc}
\hline $\boldsymbol{N}$ & $\mathbf{8}$ \\
\cline { 2 - 3 } Age (years) & $20.37 \pm 0.92$ \\
Weight $(\mathrm{kg})$ & $69.18 \pm 14.51$ \\
Height $(\mathrm{cm})$ & $168.76 \pm 5.73$ \\
BMI & $24.17 \pm 4.26$ \\
Ethnicity/Race & $1(12.5 \%)$ \\
Caucasian & $5(62.5 \%)$ \\
Hispanic & $1(12.5 \%)$ \\
Black/African American & $1(12.5 \%)$ \\
Other & $32.80 \pm 8.28$ \\
Percent fat mass $(\%)$ & $106.00 \pm 12.38$ \\
Systolic BP (mmHg) & $60.25 \pm 7.59$ \\
Diastolic BP (mmHg) & $63.25 \pm 15.37$ \\
Resting HR (bpm) &
\end{tabular}

a Data presented as mean \pm standard deviation or $N$ (\%). BMI, body mass index; HR, heart rate; BP, blood pressure. 
The nutrient composition of the day preceding testing consisted of a mean $1493 \pm 361 \mathrm{kcal}$, $46.5 \pm 14.7 \%$ of calories from carbohydrates, $20.1 \pm 5.6 \%$ from protein, and $33.4 \pm 11.0 \%$ from fat (Table 3).

Table 3. Dietary nutrient composition the day preceding testing a .

\begin{tabular}{cc}
\hline Nutrient & \\
\hline Calories (kcal) & $1493.99 \pm 361.37$ \\
Carbohydrate (\%) & $46.50 \pm 14.71$ \\
Protein (\%) & $20.09 \pm 5.57$ \\
Fat (\%) & $33.41 \pm 10.96$ \\
Saturated Fat (g) & $17.87 \pm 7.19$ \\
Monounsaturated Fat (g) & $7.71 \pm 5.36$ \\
Sugar (g) & $54.03 \pm 38.14$ \\
Fiber (g) & $18.97 \pm 9.93$ \\
Iron (mg) & $14.34 \pm 6.93$ \\
Sodium (mg) & $2692.55 \pm 1038.98$ \\
Potassium (mg) & $1022.94 \pm 490.46$ \\
Omega 3 Fatty Acid (g) & $0.27 \pm 0.17$ \\
Omega 6 Fatty Acid (g) & $1.41 \pm 0.71$ \\
Caffeine (mg) & $7.75 \pm 21.92$ \\
\hline
\end{tabular}

a Data presented as mean \pm standard deviation.

\subsection{Resting Metabolic Rate (RMR) and Thermic Effect of a Meal (TEM)}

There were significant main effects of time and meal type on $\operatorname{TEM}(F(4,66.04)=4.25, p=0.004$ and $F(1,65.98)=4.06, p=0.048$, respectively; Figure $2 \mathrm{~A}, \mathrm{~B})$.
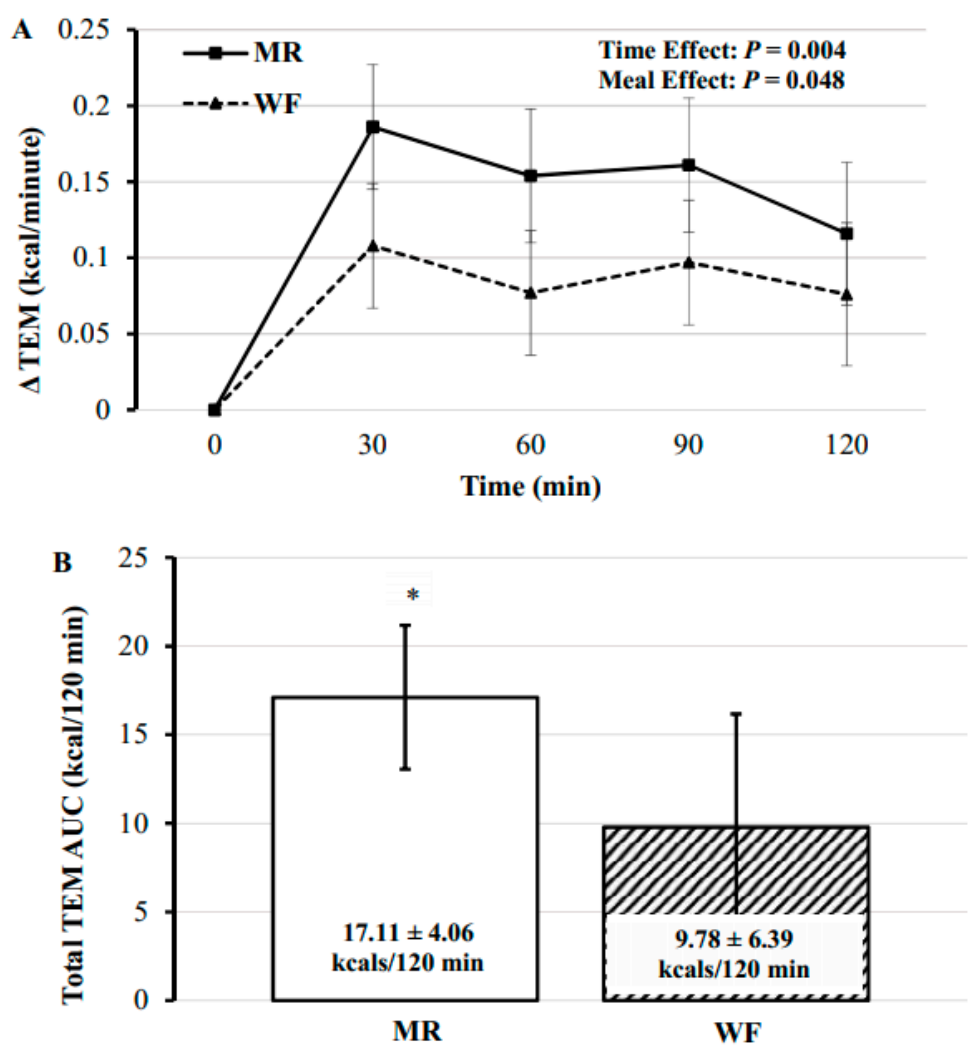

Figure 2. (A) Postprandial change in TEM across 120 min for each meal. (B) Effect of test meals on the 120 min postprandial period area under the curve (AUC) for thermic effect of meal following the two test meals. MR: meal replacement meal; WF: whole food meal. Data displayed as mean \pm standard error. ${ }^{*}$ MR significantly higher TEM than WF; $p<0.05$. 
Postprandial TEM values were significantly increased from baseline at all time points $(p \leq 0.015)$. In addition, TEM was significantly greater for MR compared to WF (percent mean difference: $7.76 \pm 3.78 \%$; absolute mean difference: $0.053 \pm 0.026 \mathrm{kcal} / \mathrm{minute}, p=0.048)$, with no significant differences at individual time points between meals $(F(4,65.89)=0.35, p=0.845$; Table 4$)$.

Table 4. RMR, TEM, and RER during the test meals ${ }^{a}$.

\begin{tabular}{|c|c|c|c|c|c|c|}
\hline Outcome Variable & Meal & Baseline & $\begin{array}{c}30 \text { min } \\
\text { TEM }\end{array}$ & $\begin{array}{c}60 \text { min } \\
\text { TEM }\end{array}$ & $\begin{array}{c}90 \text { min } \\
\text { TEM }\end{array}$ & $\begin{array}{c}120 \text { min } \\
\text { TEM }\end{array}$ \\
\hline \multirow{2}{*}{$\mathrm{RMR}^{\mathrm{b}} / \mathrm{TEM}^{\mathrm{c}}$} & $\mathrm{MR} *$ & $0.93 \pm 0.06$ & $3.42 \pm 1.83$ & $2.78 \pm 1.70$ & $7.73 \pm 1.17$ & $6.59 \pm 1.71$ \\
\hline & WF & $0.94 \pm 0.06$ & $5.93 \pm 1.71$ & $1.62 \pm 1.17$ & $4.39 \pm 1.70$ & $3.76 \pm 1.68$ \\
\hline \multirow{2}{*}{ RER $^{d}$} & $\mathrm{MR} *$ & $0.83 \pm 0.01$ & $0.89 \pm 0.02$ & $0.92 \pm 0.02$ & $0.92 \pm 0.01$ & $0.89 \pm 0.01$ \\
\hline & WF & $0.81 \pm 0.01$ & $0.87 \pm 0.03$ & $0.87 \pm 0.02$ & $0.86 \pm 0.01$ & $0.86 \pm 0.01$ \\
\hline
\end{tabular}

${ }^{a}$ Effects based on estimated marginal means, actual values displayed (mean \pm standard error). ${ }^{\mathrm{b}}$ RMR: resting
metabolic rate, kcal/minute. ${ }^{\mathrm{c}}$ TEM: Thermic effect of meal values calculated as incremental area under the curve
for 0-30, 30-60, 60-90, and $90-120-$ min periods, postprandially. $\mathrm{d}$ RER: respiratory exchange ratio. MR: meal
replacement meal; WF: whole food meal. ${ }^{*}$ Significant main effect of meal: MR $>$ WF; $p<0.05$.

\subsection{Respiratory Exchange Ratio}

There was a significant main effect of time for substrate utilization as measured by indirect calorimetry $(\operatorname{RER} ; F(4,66.15)=13.17, p<0.001)$ and meal, $(F(1,65.99)=8.31, p=0.005$; Figure 3; Table 4) Overall, WF had a significantly lower RER value compared to MR (mean difference: $-0.024 \pm 0.008$, $p=0.005)$. Similar to TEM, there were no significant differences at individual time points between meal types $(F(4,65.81)=0.208, p=0.933)$.

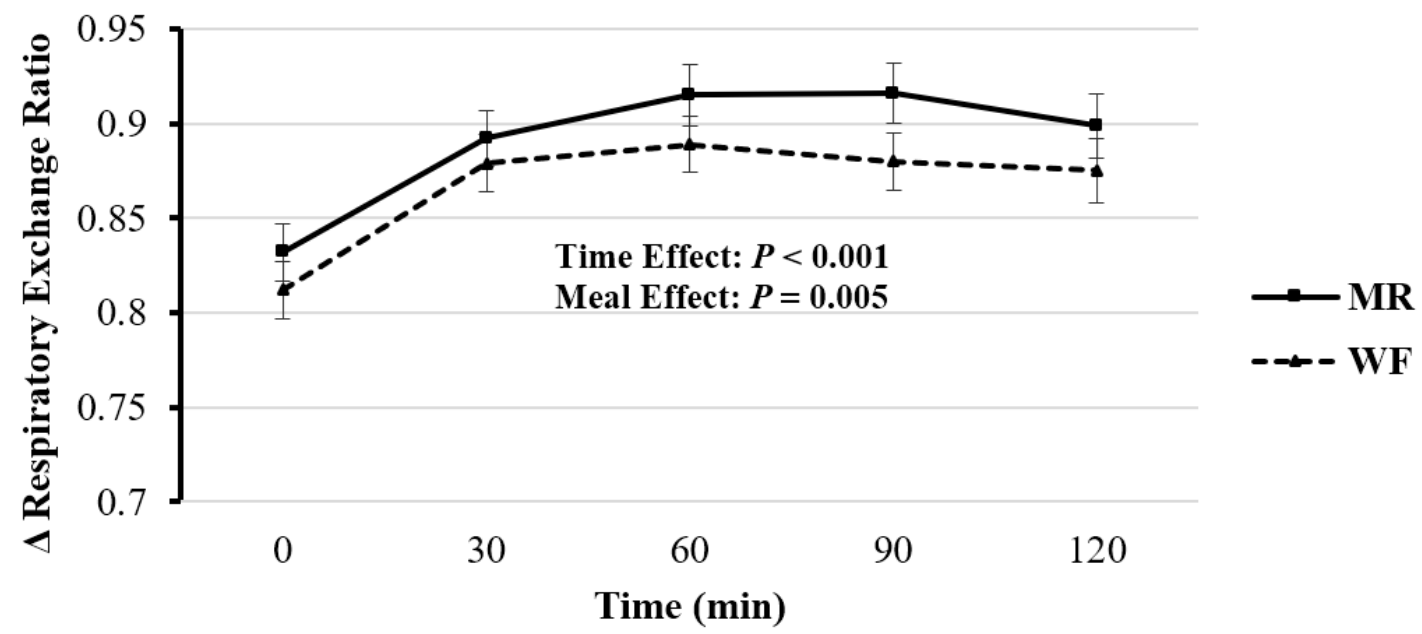

Figure 3. Postprandial change in respiratory exchange ratio $120 \mathrm{~min}$ for each meal. MR: Meal replacement meal; WF: Whole food meal. Data displayed as mean \pm standard error.

\subsection{Blood Glucose}

The main effect of time was significant, $(F(4,65.25)=16.46, p<0.001)$, with significant changes in blood glucose concentrations occurring at 30,60, and 90 min compared to baseline (mean $\Delta$ : 10.98-35.31 mg/dL, ps $\leq 0.029$; Figure 4A; Table 5). However, the effects of meal type and meal*time were not significant, $(F(1,65.17)=1.88, p=0.175$ and $F(4,64.92)=1.07, p=0.379$, respectively). Furthermore, AUC for blood glucose did not differ significantly between the two test meals, $(T(14)=-638, p=0.534$; Figure 4B). 

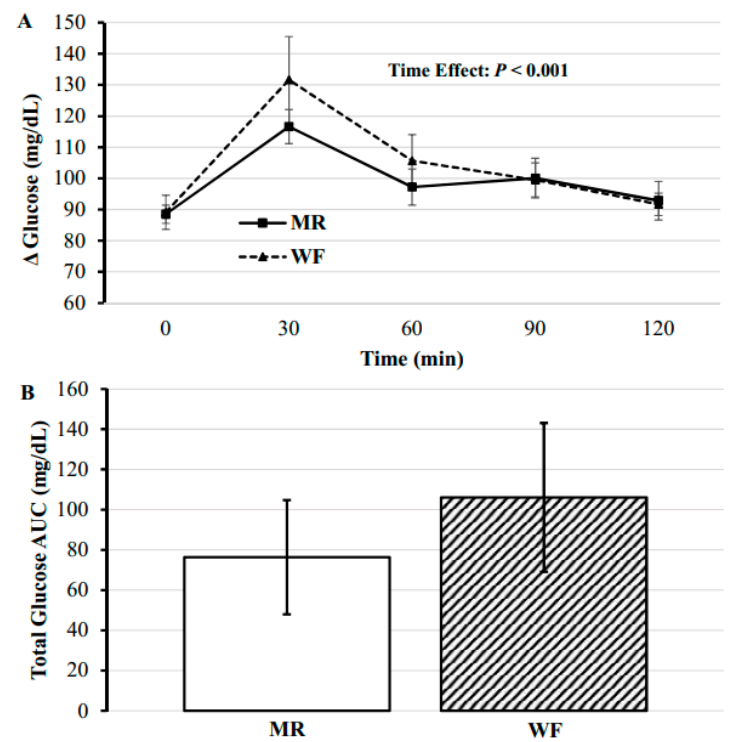

Figure 4. (A) Postprandial change in glucose across $120 \mathrm{~min}$ for each meal. (B) Effect of test meals on the 120 min postprandial period area under the curve for glucose of meal following the two test meals. MR: meal replacement meal; WF: whole food meal. Data displayed as mean \pm standard error.

Table 5. Effects of meal type on mean blood glucose at baseline and 30, 60, 90, and 120 min in the postprandial period ${ }^{\mathrm{a}}$.

\begin{tabular}{ccccccc}
\hline $\begin{array}{c}\text { Outcome } \\
\text { Variable }\end{array}$ & Meal & Baseline & $\mathbf{3 0 ~} \mathbf{~ m i n}$ & $\mathbf{6 0} \mathbf{~ m i n}$ & $\mathbf{9 0} \mathbf{~ m i n}$ & $\mathbf{1 2 0} \mathbf{~ m i n}$ \\
\hline Glucose, & MR & $88.50 \pm 2.92$ & $116.63 \pm 5.47$ & $97.22 \pm 5.79$ & $100.07 \pm 6.38$ & $92.85 \pm 6.18$ \\
$\mathrm{mg} / \mathrm{dL}$ & WF & $89.13 \pm 2.34$ & $131.63 \pm 13.89$ & $105.63 \pm 8.41$ & $99.51 \pm 5.78$ & $91.68 \pm 3.58$ \\
\hline
\end{tabular}

a Effects based on estimated marginal means, actual values displayed (means \pm standard error). MR: meal replacement meal; WF: whole food meal.

\subsection{Feelings of Hunger, Desire to Eat, and Fullness}

Pre- and post-values for the subjective ratings of hunger, desire to eat, and fullness are presented in Table 6. Both hunger and desire to eat significantly decreased after consumption of the test meals, $(F(1,24)=26.49, p<0.001$ and $F(1,24)=17.37, p<0.001$, respectively). However, there were no significant differences for hunger and desire to eat for the effect of meal $(F(1,24)=0.63, p=0.44$ and $F(1,24)=2.06, p=0.16$, respectively) or meal ${ }^{*}$ time $(F(1,24)=1.14, p=0.29$ and $F(1,24)=1.51, p=0.23$, respectively). Fullness was significantly increased after consumption of both meals, $(F(1,24)=29.85$, $p<0.001)$, but similar to hunger and desire to eat, there were no significant differences between meals, although a strong trend existed $(F(1,24)=0.19, p=0.66$, or meal*time, $F(1,24)=3.48, p=0.07)$.

Table 6. Effects of meal type on mean values of hunger and satiety rating outcome measurements at baseline and $120 \mathrm{~min}$ in the postprandial period ${ }^{\mathrm{a}}$.

\begin{tabular}{cccc}
\hline Outcome Variable & Meal & Baseline & 120 min \\
\hline \multirow{2}{*}{ Hunger (mm) } & MR & $52.00 \pm 12.27$ & $20.75 \pm 7.67$ \\
& WF & $54.13 \pm 13.09$ & $6.50 \pm 2.56$ \\
\hline \multirow{2}{*}{ Desire to eat (mm) } & MR & $70.50 \pm 10.39$ & $21.63 \pm 6.31$ \\
& WF & $46.37 \pm 12.90$ & $19.75 \pm 11.82$ \\
\hline \multirow{2}{*}{ Feeling of Fullness (mm) } & MR & $40.63 \pm 10.52$ & $67.75 \pm 11.00$ \\
& WF & $29.88 \pm 11.40$ & $85.13 \pm 4.04$
\end{tabular}

a Effects based on estimated marginal means, actual values displayed (means \pm standard error). MR: meal replacement meal; WF: whole food meal. 


\section{Discussion}

The primary aim of this study was to compare a WF to a MR meal matched for energy and macronutrient content on the thermic response of a meal (TEM), respiratory exchange ratio (RER), blood glucose, and fullness, hunger, and satiety ratings. The main findings of the current study reveal that: (1) a MR meal elicited a significantly larger thermogenic response and (2) had a higher RER (greater carbohydrate oxidation) compared to the WF meal. However, blood glucose and subjective ratings of fullness, hunger, and satiety did not differ significantly between the two meals. Taken together, the current findings demonstrate an acute MR meal challenge produces a significantly higher thermogenic response (calories burned) and higher carbohydrate oxidation compared to a WF meal of equal caloric and macronutrient composition. Further, a MR meal is comparable in blood glucose response and sensation of fullness, hunger, and satiety compared to a whole food meal. These findings may have important implications regarding how specific dietary advice is recommended based on incorporating MR for both weight control, especially among groups at higher risk of weight gain/obesity, such as younger adults in university/college settings.

\subsection{Thermic Effect of a Meal (TEM)}

The main findings of the current study indicate there was a significant main effect in thermogenesis following consumption of the test meals, with an MR meal displaying an increased thermogenic response compared to a WF meal. Our lab has previously demonstrated a significantly greater TEM response (67-100\%) following eight weeks of a higher protein intake (34\% of total calories) and frequency (six meals/day), known as 'protein pacing', with the support of three nutritionally engineered MR meals of liquid shakes and bars compared to three traditional unrefined/unprocessed WF meals/day [12]. The increased TEM was associated with significant reductions in total and abdominal body fat and increased lean body mass. More recent work from our laboratory has shown a gluten-free (GF) meal reduced TEM compared to a WF meal and an ultra PF meal [14]. To our knowledge, the current study is the first direct comparison of an acute meal challenge of iso-caloric/macronutrient meals containing nutritionally engineered MR foods (shakes and bars) versus unrefined WF. Recent data by Hall and colleagues [30] highlighted the ability of a diet composed of ultra-PF to promote increased energy intake (via increased carbohydrate and fat consumption) and weight gain compared to an unprocessed WF diet matched for calories, energy density, macronutrients, sugar, sodium, and fiber. Ultra PF have been defined as, "formulations mostly of cheap industrial sources of dietary energy and nutrients plus additives, using a series of processes" and containing minimal whole foods [31]. While the MR condition in the present study may be considered processed, much of the ingredients are of generally high nutritional values, including $32 \mathrm{~g}$ ( $24 \%$ of total kcal) of protein. Further, much of the meal replacement shakes and bars available to consumers have been 'nutritionally engineered' for improved health outcomes compared to ultra PF formulated for increased appetitive properties and often high in calories, salt, sugar, and fat [32-34]. According to the 'protein leverage hypothesis' proposed by Simpson and Raudenheimer [35], a reduced protein density diet may increase intake of ultra PF and drive energy overconsumption and obesity, a finding supported by some [36], but not all investigators [30]. In support of our findings, recent data comparing processed MR formulations from either diary or plant sources showed significantly higher TEM in comparison to carbohydrate controls in young healthy volunteers $[37,38]$.

In the current study, energy and macronutrient composition were well-matched with both meal formulations, including identical protein amounts (32 g), although sugar (WF: $27.6 \mathrm{~g}$ vs. MR: $50.7 \mathrm{~g}$ ) and fiber content (WF: $19.7 \mathrm{~g}$ vs. MR: $1.7 \mathrm{~g}$ ), were different. In contrast to our results, an acute crossover meal challenge using an iso-caloric $(600 \mathrm{kcal})$ sugar only beverage vs. a mixed-nutrient beverage ( $17 \%$ protein; $67 \%$ carbohydrate; $17 \%$ fat) found TEM to be significantly lower in the sugar only beverage [39]. While the meal formulations in the current study focused on WF versus MR, future studies should explore the effects of varying amounts and types of sugar, including glycemic index and load, on TEM. In addition to sugar, the difference in fiber content (and type) may also 
affect TEM on and acute and longer-term basis using WF and MR interventions. Specifically, research from our laboratory has shown an acute meal challenge of protein combined with resistant starch fiber (RS4) significantly increases substrate oxidation compared to no fiber control meal. Thus, future investigations should explore fiber content and type and its potential impact on TEM, as well as the gut microbiota and microbially-derived products (e.g., short-chain fatty acids). Another important factor that may have influenced our findings was the potential difference in digestion rates of the two meals. While tube-delivered meals have been reported to not differ in magnitude or duration of TEM after orally ingested meals [40], future research should more accurately compare the solid vs. liquid formats of meals. Lastly, it's possible other components not controlled for in the current study, such as micronutrients, may have contributed to the change in TEM.

TEM represents the energy expenditure of processing and storing food, as well as the metabolic effects of the influx of nutrients. It may be possible to alter TEM as a weight-loss tool in both research and clinical settings, however the current body of literature remains very limited [41]. The findings of our study provide some of the first evidence that a nutritionally engineered MR may offer slightly enhanced postprandial thermogenesis (energy expenditure) compared to an iso-caloric/macronutrient WF breakfast. Over time, this increase in TEM may result in significant weight loss.

\subsection{Respiratory Exchange Ratio (RER)}

While both meals contained the same amount of carbohydrate $(69 \mathrm{~g})$ and fat (16 g), the MR meal showed an overall greater RER value compared to the whole food meal. As with TEM, to our knowledge, no study has directly compared the effects of these two iso-caloric, macronutrient matched meal formats on RER. It is likely that greater sugar content in the MR may have partially been responsible for these findings. Indeed, this finding aligns with a number of previous acute randomized cross-over trials investigating energy expenditure, substrate utilization, and RER [42]. For example, iso-caloric mixed-meal challenges using higher vs. lower glycemic index and glycemic load meals also elicited greater RER levels [43]. While glycemic index/load has been a nutrition topic of interest for decades, matching meals for protein and macronutrients presents a fascinating new area of research with important energy balance implications [44].

\subsection{Blood Glucose Response}

The current study showed no differences among the two test meals on blood glucose response, suggesting nutrient composition and meal form, including the degree of processing, had little influence on blood glucose. This finding corroborates our previous research and others showing acute meal ingestion shows similar blood glucose responses to varying processed meals $[13,45,46]$, though, there is research that conflicts with these findings [47]. In contrast to the current study, most previous research reporting lower glucose responses to meal ingestion, used test meals with varying amounts of fiber, protein, or fat [48]. While the macronutrient compositions of the present test meals were nearly identical, the difference in meal form and sugar amount were notable differences between the two meals. Indeed, there is strong agreement that ultra-processing disrupts the physical structure of intact food, making the macromolecular structure more simple and thus easier and faster to digest, resulting in more rapid increases in plasma glucose and insulin [49]. While insulin was not measured, the current study does not support that a nutritionally engineered meal adversely affects glycemic control compared to a whole food meal, at least in young healthy, insulin-sensitive women.

\subsection{Feelings of Satiety, Hunger, Desire to Eat}

As previously noted, there was no significance found between the two meals in regards to desire to eat, satiety, and hunger. In relation to the difference noted in the thermogenic response between the two test meals, TEM has previously been suggested as one of the mechanisms that influences appetite sensations, including satiety [50]. Further, acute meal challenges comparing high-sugar to mixed-nutrient beverages have reported significantly lower levels of satiety [39]. However, in a more 
recent meta-analysis no associations were found between change in TEM and various appetite and satiety measures [51]. Findings from the present study, while null, are nonetheless intriguing and novel as a processed, nutritionally engineered MR had similar hunger, satiety, and fullness ratings compared to a high-quality, unprocessed WF meal. While future research should assess these measures on additional acute time points (instead of pre/post), these findings were not surprising considering the matched energy and macronutrient compositions of the two meals.

\subsection{Limitations}

There are several limitations to the current study. The relatively small sample size, age range, and ethnicities of participants limits the extrapolation of our results. However, due to the use of a randomized cross-over design, the results of this research are compelling and warrant further investigation with stronger powered sample sizes with participants of varying ages and ethnicities. Another limitation was the VAS questionnaires were administered pre/post-testing and therefore more time-sensitive changes in response may have been missed. Finally, this acute study spanned a time frame of $120 \mathrm{~min}$. Therefore, TEM measures beyond $2 \mathrm{~h}$ may provide further information and insight regarding the differences between a WF and MR meal. It's important to note, previous studies highlight the major part of TEM takes place during the first few hours after ingestion of a meal $[52,53]$.

\section{Conclusions}

In conclusion, our novel findings suggest that a processed, nutritionally engineered MR increases postprandial thermogenesis and RER compared to a high-quality, unprocessed WF meal of equal caloric and macronutrient composition. Importantly, we found no difference in the postprandial blood glucose response or subjective ratings of satiety, hunger, and desire to eat between the two meals, highlighting the similarity of these meals. While a diet composed of ultra PF, yet similar total calories and low in nutrient value may promote weight gain and obesity, we show for the first time in an acute meal challenge that a processed, nutritionally engineered MR meal may offer an effective strategy for obesity prevention and treatment.

Author Contributions: Conceptualization, C.R., K.T., and P.J.A.; Data curation, C.R., K.T., and P.J.A.; Formal analysis, A.E.M. and P.J.A.; Funding acquisition, C.R., K.T., and P.J.A.; Investigation, C.R., K.T., and P.J.A.; Methodology, C.R., K.T., A.E.M., and P.J.A.; Project administration, P.J.A.; Resources, P.J.A.; Supervision, P.J.A.; Writing-original draft, A.E.M. and P.J.A.; Writing-review and editing, C.R., K.T., A.E.M., and P.J.A. All authors have read and agreed to the published version of the manuscript.

Funding: This research received no external funding.

Acknowledgments: We are thankful for the time and effort put forth by all of the study volunteers during the entire study. We are grateful to the Health \& Human Physiological Sciences Department for providing partial funding for this study.

Conflicts of Interest: All authors have no financial interests regarding the outcomes of this investigation. All authors declare no conflict of interests.

\begin{tabular}{|c|c|}
\hline \multicolumn{2}{|c|}{ Abbreviations } \\
\hline The fo & ig abbreviations are used in this manuscri \\
\hline DXA & Dual-Energy X-ray Absorptiometry scan \\
\hline MR & meal replacement meal \\
\hline WF & whole food \\
\hline RMR & resting metabolic rate \\
\hline TEM & thermic effect of a meal \\
\hline BMI & body mass index \\
\hline RER & respiratory exchange ratio \\
\hline AUC & area under the curve \\
\hline VAS & visual analog scale \\
\hline
\end{tabular}




\section{References}

1. Monteiro, C.A.; Moubarac, J.C.; Cannon, G.; Ng, S.W.; Popkin, B. Ultra-processed products are becoming dominant in the global food system. Obes. Rev. 2013, 14, 21-28. [CrossRef]

2. Baker, P.; Friel, S. Food systems transformations, ultra-processed food markets and the nutrition transition in Asia. Glob. Health 2016, 12, 80. [CrossRef]

3. Poti, J.M.; Braga, B.; Qin, B. Ultra-processed food intake and obesity: What really matters for health-processing or nutrient content? Curr. Obes. Rep. 2017, 6, 420-431. [CrossRef]

4. Monteiro, C.A.; Moubarac, J.C.; Levy, R.B.; Canella, D.S.; Louzada, M.L.D.C.; Cannon, G. Household availability of ultra-processed foods and obesity in nineteen European countries. Public Health Nutr. 2018, 21, 18-26. [CrossRef]

5. Moubarac, J.C.; Batal, M.; Martins, A.P.; Claro, R.; Levy, R.B.; Cannon, G.; Monteiro, C. Processed and ultra-processed food products: Consumption trends in Canada from 1938 to 2011. Can. J. Diet. Pract. Res. 2014, 75, 15-21. [CrossRef] [PubMed]

6. Cowan, A.E.; Jun, S.; Gahche, J.J.; Tooze, J.A.; Dwyer, J.T.; Eicher-Miller, H.A.; Bhadra, A.; Guenther, P.M.; Potischman, N.; Dodd, K.W.; et al. Dietary supplement use differs by socioeconomic and health-related characteristics among U.S. adults, NHANES 2011-2014. Nutrients 2018, 10, 1114. [CrossRef] [PubMed]

7. Davis, L.M.; Coleman, C.; Kiel, J.; Rampolla, J.; Hutchisen, T.; Ford, L.; Andersen, W.S.; Hanlon-Mitola, A. Efficacy of a meal replacement diet plan compared to a food-based diet plan after a period of weight loss and weight maintenance: A randomized controlled trial. Nutr. J. 2010, 9, 11. [CrossRef] [PubMed]

8. Astbury, N.M.; Piernas, C.; Hartmann-Boyce, J.; Lapworth, S.; Aveyard, P.; Jebb, S.A. A systematic review and meta-analysis of the effectiveness of meal replacements for weight loss. Obes. Rev. 2019, 20, 569-587. [CrossRef] [PubMed]

9. Klempel, M.C.; Kroeger, C.M.; Bhutani, S.; Trepanowski, J.F.; Varady, K.A. Intermittent fasting combined with calorie restriction is effective for weight loss and cardio-protection in obese women. Nutr. J. 2012, 11, 98. [CrossRef] [PubMed]

10. Arciero, P.J.; Edmonds, R.; He, F.; Ward, E.; Gumpricht, E.; Mohr, A.; Ormsbee, M.J.; Astrup, A. Protein-pacing caloric-restriction enhances body composition similarly in obese men and women during weight loss and sustains efficacy during long-term weight maintenance. Nutrients 2016, 8, 476. [CrossRef]

11. Zuo, L.; He, F.; Tinsley, G.M.; Pannell, B.K.; Ward, E.; Arciero, P.J. Comparison of high-protein, intermittent fasting low-calorie diet and heart healthy diet for vascular health of the obese. Front. Physiol. 2016, 7, 350. [CrossRef]

12. Arciero, P.J.; Ormsbee, M.J.; Gentile, C.L.; Nindl, B.C.; Brestoff, J.R.; Ruby, M. Increased protein intake and meal frequency reduces abdominal fat during energy balance and energy deficit. Obesity 2013, 21, 1357-1366. [CrossRef] [PubMed]

13. Gentile, C.L.; Ward, E.; Holst, J.J.; Astrup, A.; Ormsbee, M.J.; Connelly, S.; Arciero, P.J. Resistant starch and protein intake enhances fat oxidation and feelings of fullness in lean and overweight/obese women. Nutr. J. 2015, 14, 113. [CrossRef] [PubMed]

14. Dioneda, B.; Healy, M.; Paul, M.; Sheridan, C.; Mohr, A.E.; Arciero, P.J. A gluten-free meal produces a lower postprandial thermogenic response compared to an iso-energetic/macronutrient whole food or processed food meal in young women: A single-blind randomized cross-over trial. Nutrients 2020, 12, 2035. [CrossRef] [PubMed]

15. DiMeglio, D.P.; Mattes, R.D. Liquid versus solid carbohydrate: Effects on food intake and body weight. Int. J. Obes. Relat. Metab. Disord. 2000, 24, 794-800. [CrossRef]

16. Mourao, D.M.; Bressan, J.; Campbell, W.W.; Mattes, R.D. Effects of food form on appetite and energy intake in lean and obese young adults. Int. J. Obes. 2007, 31, 1688-1695. [CrossRef]

17. Mattes, R.D.; Campbell, W.W. Effects of food form and timing of ingestion on appetite and energy intake in lean young adults and in young adults with obesity. J. Am. Diet. Assoc. 2009, 109, 430-437. [CrossRef]

18. Almiron-Roig, E.; Flores, S.Y.; Drewnowski, A. No difference in satiety or in subsequent energy intakes between a beverage and a solid food. Physiol. Behav. 2004, 82, 671-677. [CrossRef]

19. Bolton, R.P.; Heaton, K.W.; Burroughs, L.F. The role of dietary fiber in satiety, glucose, and insulin: Studies with fruit and fruit juice. Am. J. Clin. Nutr. 1981, 34, 211-217. [CrossRef] 
20. Houchins, J.A.; Tan, S.Y.; Campbell, W.W.; Mattes, R.D. Effects of fruit and vegetable, consumed in solid vs beverage forms, on acute and chronic appetitive responses in lean and obese adults. Int. J. Obes. 2013, 37, 1109-1115. [CrossRef]

21. Tieken, S.M.; Leidy, H.J.; Stull, A.J.; Mattes, R.D.; Schuster, R.A.; Campbell, W.W. Effects of solid versus liquid meal-replacement products of similar energy content on hunger, satiety, and appetite-regulating hormones in older adults. Horm. Metab. Res. 2007, 39, 389-394. [CrossRef] [PubMed]

22. Stull, A.J.; Apolzan, J.W.; Thalacker-Mercer, A.E.; Iglay, H.B.; Campbell, W.W. Liquid and solid meal replacement products differentially affect postprandial appetite and food intake in older adults. J. Am. Diet. Assoc. 2008, 108, 1226-1230. [CrossRef] [PubMed]

23. Leidy, H.J.; Apolzan, J.W.; Mattes, R.D.; Campbell, W.W. Food form and portion size affect postprandial appetite sensations and hormonal responses in healthy, nonobese, older adults. Obesity 2010, 18, $293-299$. [CrossRef] [PubMed]

24. Apolzan, J.W.; Leidy, H.J.; Mattes, R.D.; Campbell, W.W. Effects of food form on food intake and postprandial appetite sensations, glucose and endocrine responses, and energy expenditure in resistance trained $\mathrm{v}$. sedentary older adults. Br. J. Nutr. 2011, 106, 1107-1116. [CrossRef] [PubMed]

25. Leidy, H.J.; Bales-Voelker, L.I.; Harris, C.T. A protein-rich beverage consumed as a breakfast meal leads to weaker appetitive and dietary responses v. a protein-rich solid breakfast meal in adolescents. Br. J. Nutr. 2011, 106, 37-41. [CrossRef] [PubMed]

26. Myers, C.; McCartney, D.; Desbrow, B.; Khalesi, S.; Irwin, C. Consumption of a smoothie or cereal-based breakfast: Impact on thirst, hunger, appetite and subsequent dietary intake. Int. J. Food Sci. Nutr. 2020, 18, 1-11. [CrossRef]

27. Deforche, B.; Van Dyck, D.; Deliens, T.; De Bourdeaudhuij, I. Changes in weight, physical activity, sedentary behaviour and dietary intake during the transition to higher education: A prospective study. Int. J. Behav. Nutr. Phys. Act. 2015, 12, 16. [CrossRef]

28. Beaudry, K.M.; Ludwa, I.A.; Thomas, A.M.; Ward, W.E.; Falk, B.; Josse, A.R. First-year university is associated with greater body weight, body composition and adverse dietary changes in males than females. PLoS ONE 2019, 14, e0218554. [CrossRef]

29. Arciero, P.J.; Gentile, C.L.; Pressman, R.; Everett, M.; Ormsbee, M.J.; Martin, J.; Santamore, J.; Gorman, L.; Fehling, P.C.; Vukovich, M.D.; et al. Moderate protein intake improves total and regional body composition and insulin sensitivity in overweight adults. Metabolism 2008, 57, 757-765. [CrossRef]

30. Hall, K.D.; Ayuketah, A.; Brychta, R.; Cai, H.; Cassimatis, T.; Chen, K.Y.; Chung, S.T.; Costa, E.; Courville, A.; Darcey, V.; et al. Ultra-processed diets cause excess calorie intake and weight gain: An inpatient randomized controlled trial of ad libitum food intake. Cell Metab. 2019, 30, 67-77.e3. [CrossRef]

31. Monteiro, C.A.; Cannon, G.; Moubarac, J.C.; Levy, R.B.; Louzada, M.L.C.; Jaime, P.C. The UN ecade of Nutrition, the NOVA food classification and the trouble with ultra-processing. Public Health Nutr. 2018, 21, 5-17. [CrossRef] [PubMed]

32. Poti, J.M.; Mendez, M.A.; Ng, S.W.; Popkin, B.M. Is the degree of food processing and convenience linked with the nutritional quality of foods purchased by US households? Am. J. Clin. Nutr. 2015, 101, 1251-1262. [CrossRef] [PubMed]

33. Schulte, E.M.; Avena, N.M.; Gearhardt, A.N. Which foods may be addictive? The roles of processing, fat content, and glycemic load. PLoS ONE 2015, 10, e0117959. [CrossRef] [PubMed]

34. Schulte, E.M.; Smeal, J.K.; Gearhardt, A.N. Foods are differentially associated with subjective effect report questions of abuse liability. PLOS ONE 2017, 12, e0184220. [CrossRef]

35. Simpson, S.J.; Raubenheimer, D. Obesity: The protein leverage hypothesis. Obes. Rev. 2005, 6, 133-142. [CrossRef]

36. Martínez Steele, E.; Raubenheimer, D.; Simpson, S.J.; Baraldi, L.G.; Monteiro, C.A. Ultra-processed foods, protein leverage and energy intake in the USA. Public Health Nutr. 2018, 21, 114-124. [CrossRef]

37. Neumann, B.L.; Dunn, A.; Johnson, D.; Adams, J.D.; Baum, J.I. Breakfast macronutrient composition influences thermic effect of feeding and fat oxidation in young women who habitually skip breakfast. Nutrients 2016, 8, 490. [CrossRef]

38. Melson, C.E.; Nepocatych, S.; Madzima, T.A. The effects of whey and soy liquid breakfast on appetite response, energy metabolism, and subsequent energy intake. Nutrition 2019, 61, 179-186. [CrossRef] 
39. St-Onge, M.P.; Rubiano, F.; DeNino, W.F.; Jones, A., Jr.; Greenfield, D.; Ferguson, P.W.; Akrabawi, S.; Heymsfield, S.B. Added thermogenic and satiety effects of a mixed nutrient vs a sugar-only beverage. Int. J. Obes. Relat. Metab. Disord. 2004, 28, 248-253. [CrossRef]

40. Hill, J.O.; DiGirolamo, M.; Heymsfield, S.B. Thermic effect of food after ingested versus tube-delivered meals. Am. J. Physiol. 1985, 248, E370-E374. [CrossRef]

41. Calcagno, M.; Kahleova, H.; Alwarith, J.; Burgess, N.N.; Flores, R.A.; Busta, M.L.; Barnard, N.D. The thermic effect of food: A review. J. Am. Coll. Nutr. 2019, 38, 547-551. [CrossRef]

42. Raben, A. Should obese patients be counselled to follow a low-glycaemic index diet? No. Obes. Rev. 2002, 3, 245-256. [CrossRef] [PubMed]

43. Scazzina, F.; Del Rio, D.; Benini, L.; Melegari, C.; Pellegrini, N.; Marcazzan, E.; Brighenti, F. The effect of breakfasts varying in glycemic index and glycemic load on dietary induced thermogenesis and respiratory quotient. Nutr. Metab. Cardiovasc. Dis. 2011, 21, 121-125. [CrossRef] [PubMed]

44. Sun, F.H.; Li, C.; Zhang, Y.J.; Wong, S.H.; Wang, L. Effect of glycemic index of breakfast on energy intake at subsequent meal among healthy people: A meta-analysis. Nutrients 2016, 8, 37. [CrossRef] [PubMed]

45. Coelho, M.O.C.; Monteyne, A.J.; Kamalanathan, I.D.; Najdanovic-Visak, V.; Finnigan, T.J.A.; Stephens, F.B.; Wall, B.T. Short-communication: Ingestion of a nucleotide-rich mixed meal increases serum uric acid concentrations but does not affect postprandial blood glucose or serum insulin responses in young adults. Nutrients 2020, 12, 1115. [CrossRef] [PubMed]

46. Ranganathan, S.; Champ, M.; Pechard, C.; Blanchard, P.; Nguyen, M.; Colonna, P.; Krempf, M. Comparative study of the acute effects of resistant starch and dietary fibers on metabolic indexes in men. Am. J. Clin. Nutr. 1994, 59, 879-883. [CrossRef]

47. Kim, Y.; Keogh, J.B.; Clifton, P.M. Differential effects of red meat/refined grain diet and dairy/chicken/nuts/whole grain diet on glucose, insulin and triglyceride in a randomized crossover study. Nutrients 2016, 8, 687. [CrossRef]

48. Giezenaar, C.; Lange, K.; Hausken, T.; Jones, K.L.; Horowitz, M.; Chapman, I.; Soenen., S. Acute effects of substitution, and addition, of carbohydrates and fat to protein on gastric emptying, blood glucose, gut hormones, appetite, and energy intake. Nutrients 2018, 10, 1451. [CrossRef]

49. Nardocci1, N.; Leclerc, B.S.; Louzada, M.L.; Monteiro, C.A.; Batal, M.; Moubarac, J.C. Consumption of ultra-processed foods and obesity in Canada. Can. J. Public Health 2019, 110, 4-14. [CrossRef]

50. Strominger, J.L.; Brobeck, J.R. A mechanism of regulation of food intake. Yale J. Biol. Med. 1953, 25, 383-390.

51. Ravn, A.M.; Gregersen, N.T.; Christensen, R.; Rasmussen, L.G.; Hels, O.; Belza, A.; Raben, A.; Larsen, T.M.; Toubro, S.; Astrup, A. Thermic effect of a meal and appetite in adults: An individual participant data meta-analysis of meal-test trials. Food Nutr. Res. 2013, 57, 19676. [CrossRef] [PubMed]

52. Reed, G.W.; Hill, J.O. Measuring the thermic effect of food. Am. J. Clin. Nutr. 1996, 63, 164-169. [CrossRef] [PubMed]

53. Weststrate, J.A. Resting metabolic rate and diet-induced thermogenesis: A methodological reappraisal. Am. J. Clin. Nutr. 1993, 58, 592-601. [CrossRef] [PubMed]

(C) 2020 by the authors. Licensee MDPI, Basel, Switzerland. This article is an open access article distributed under the terms and conditions of the Creative Commons Attribution (CC BY) license (http://creativecommons.org/licenses/by/4.0/). 